\title{
Prevention of healthcare-associated infections in paediatric intensive care unit
}

\author{
Anand Wagh ${ }^{1} \cdot$ Ajay Sinha ${ }^{2}$
}

Received: 6 July 2018 / Accepted: 9 July 2018 / Published online: 18 August 2018

(C) Springer-Verlag GmbH Germany, part of Springer Nature 2018

\begin{abstract}
Introduction Healthcare-associated infections put a tremendous burden on health services around. In the last few decades, there has been a tremendous advancement in foetal and maternal care, and it has led to premature babies born as early as 25 weeks of gestation being nursed and cared for in neonatal and paediatric intensive care units. However, these children can pick up a number of uncommon and rare hospital-acquired infections including central nervous system (CNS) infections.

Methods The authors have given their own insight as to the prevention of healthcare-associated infections in paediatric intensive care settings and reviewed the current literature on the topic.

Conclusions Healthcare-associated infections are largely preventable provided adequate prevention and protective measures are put in place and prevention guidelines are stritctly followed.
\end{abstract}

Keywords Healthcare-associated infections $\cdot$ Nosocomial infections

\section{Introduction}

Critically ill children cared on paediatric intensive care unit are predisposed to healthcare-associated infection (HCAI) (Figs. 1, 2, 3, and 4). Patients admitted with primary neurological disorder and post neurosurgical intervention pose unique vulnerability to infection and challenges of diagnosis as well as treatment. Nosocomial infections are a major and potentially preventable cause of morbidity and increased cost in paediatric intensive care units (PICUs). In this review, we summarise our approach to preventing HCAI on the PICU.

\section{Epidemiology}

Healthcare-associated infections (HCAIs) are inevitable collateral damage of intensive care support. The reported prevalence varies between resource rich and resource poor countries. Reported prevalence is as low as $4 \%$ in the USA and $5.7 \%$ in

Ajay Sinha

Ajay.sinha@alderhey.nhs.uk

1 Department of Paediatric Intensive Care, Alder hey Childrens' NHS Foundation trust, Liverpool, UK

2 Department of Neurosurgery, Alder hey Childrens' NHS Foundation trust, Liverpool, UK the UK [1-3]. Highest prevalence are in paediatric intensive care (15.5\%) and neonatal intensive care unit (10.7\%) in developing countries $[2,10]$. Comparison of infection rates across paediatric and neonatal intensive care units would be difficult and prone to inaccuracies because of variations in PICU physical structures and severity of patient illness. As opposed to catheter-related urinary tract infection and ventilator-associated infection being more common on adult neuro-intensive care units, blood stream infections and ventilator-associated pneumonia are predominant HCAIs on paediatric intensive care unit [4].

\section{Risk factors}

Children critical enough to need intensive care treatment are most vulnerable. Younger age, non-elective admissions and patient-harbouring conditions with expected higher risk of mortality at admission to intensive care are known risk factors for HCAI [10]. As number of interventions and organ system support escalates, there would be a greater risk of HCAI. Source of infections would be endogenous microorganisms that are commensals or exogenous from the intensive care environment. Interactions between susceptible hosts, a more virulent hospital-acquired infective agent and facilitated by PICU environmental factors complete the chain of infection [8]. 


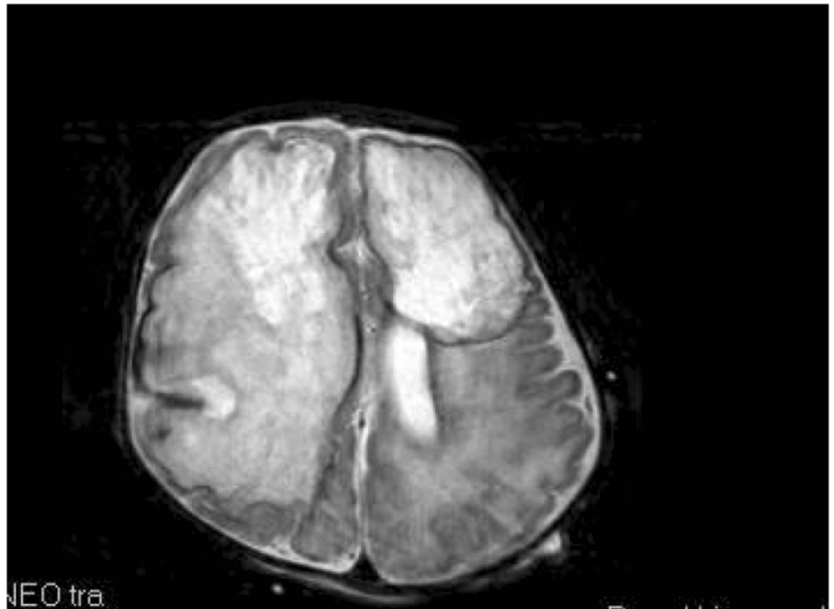

Fig. 1 Initial MRI T2WI-bilateral abscess (preterm twin prolonged PICU stay-Citrobacter infection)

\section{Host factors}

Age - neonates and infants have immature immune system and blood stream infections are more common in this group of patients [20, 24]. Children older than 5 years and adolescents run similar risk of HCAI as adults with Ventilator Associated Pneumonia and Catheter associated Urinary Tract Infection being more common [1,24].

Immunity-use of glucocorticoids on neuro-intensive care or other immunosuppressive agents after organ transplantation makes patient more vulnerable [5, 12]. In children, immunisation status affects host defences. The higher the severity of illness score, the greater will be the risk of contracting HCAI [24].

Breach in integrity of skin and mucosa e.g. indwelling catheters [central lines, drains] or surgical site will facilitate microorganisms invasion. Loss of natural defence mechanisms like effective cough and mucociliary clearance of

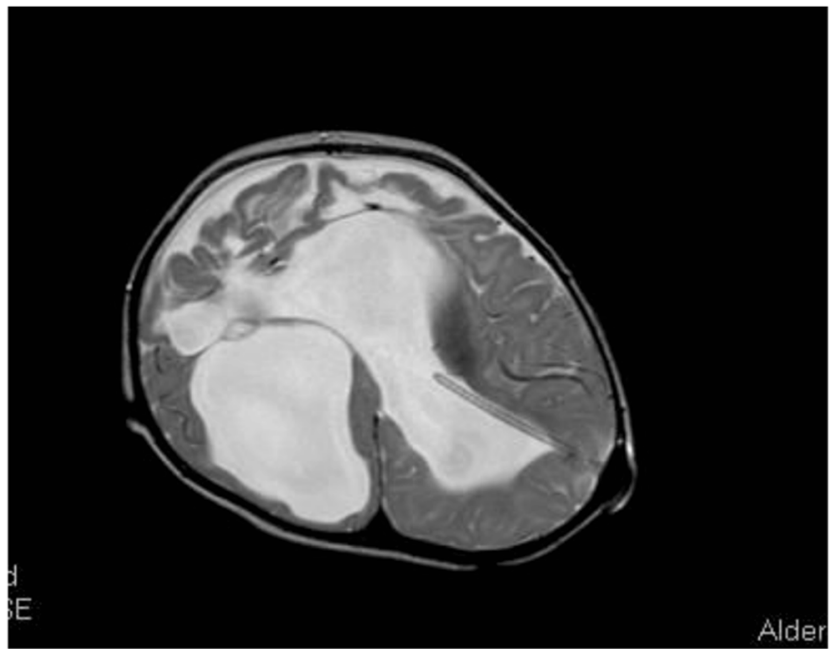

Fig. 2 Final MRI T2WI-post craniotomy for abscess excision and VP shunt for hydrocephalus

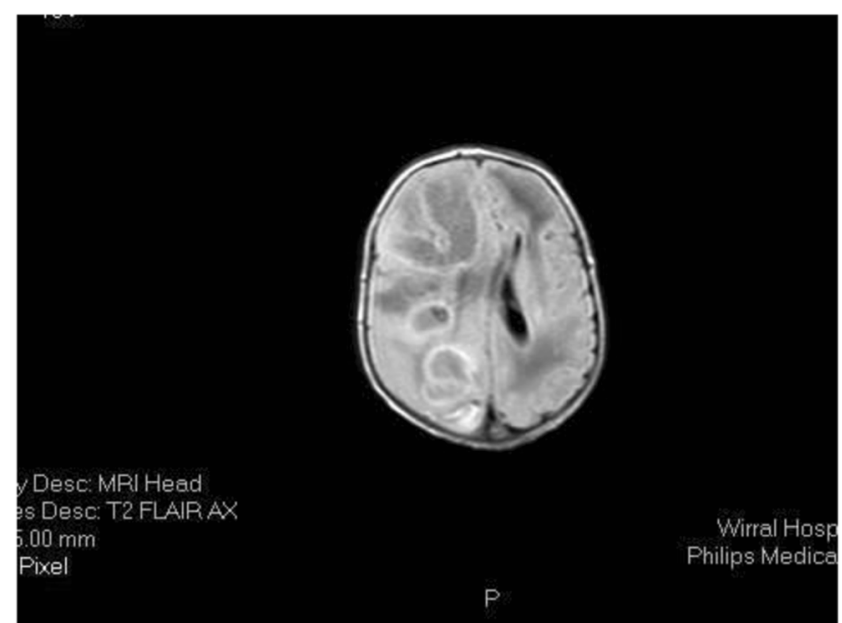

Fig. 3 MRI T2WI flair multiloculated abscess (-E. coli sepsis in neonate)-NICU-acquired infections

secretions with ventilation and sedation or reduction in gastric acidity with $\mathrm{H} 2$ blockers [12] and indwelling nasogastric tubes can lead commensals to cause invasive infections.

\section{Environmental factors}

Transmission of infection is caused by the same pair of hands which care for the patient on intensive care unit. Various factors like high patient to healthcare staff ratio and device utilisation ratio, less ideal infection prevention and control prevention practices, carers and visitors immunisation status and reservoirs of infection (equipment and devices) affect exposure to nosocomial organisms. Hospital practice of giving prophylactic antibiotics which change the commensal flora and cause overgrowth of pathogen would affect the prevalence of HCAI.

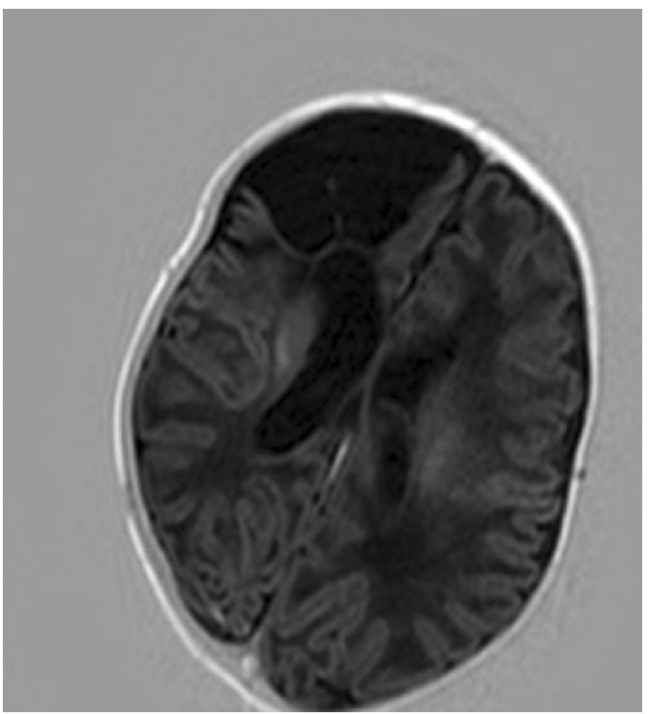

Fig. 4 MRI T1WI-post surgical drainage-delayed scan showing frontal lobe encepalomalacia 
Chart 1 Infection control programme model $[12,23]$
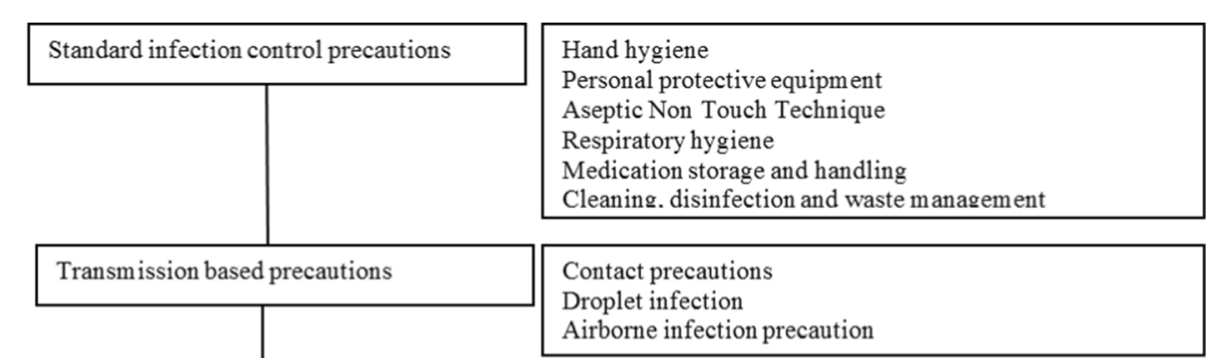

Contact precautions

Droplet infection

Airborne infection precaution

Education and training of healthcare staff

Chart 1. Infection control programme model $[12,24]$

\section{Transmission of micro organisms in paediatric intensive care}

Pathogenic microbes are transmitted by one of the three routes, contact (direct or indirect), droplet and airborne spread $[8,17]$. These three routes of transmission help stratify the infection control measures.

Direct contact of infected or carrier host with susceptible host or contamination of host environment due to poor hand hygiene leads to direct contact and spread of microorganisms.

Droplets ( $>5 \mu \mathrm{m}$ in diameter) from respiratory tract of a potentially infected healthcare worker can lead to inoculation in a susceptible host [7]. Droplets do not remain suspended in air and do not propel more than a meter in distance, and strict contact precautions prevent cross infection.

Spread of infection by aerosolisation (airborne particles $<5 \mu \mathrm{m}$ ) caused dissemination of microorganisms by air current e.g. varicella outbreak on intensive care unit. Such patients require source isolation cubicles with controlled air currents [7].

\section{Types of nosocomial infections and pathogens}

Most common type of HCAI is blood stream infection associated with central lines [45\%], followed by ventilatorassociated lower respiratory tract infections [24].

\section{Central line-associated blood stream infections (CLABSI)} Around $50 \%$ of HCAI in neonates and infants are blood stream infections. Gram-positive bacteria-Coagulase Negative Staphylococci (CONS) and Staphylococcus aureus are the most common accounting for one third of blood stream infections [9, 24]. Gram-negative bacteria including Enterobacteraciae and non fermienting bacteria such as
Pseudomonas sp., Acinatobacter Sp and Stenotrophomonas sp. are responsible for $25 \%$ of BSI. Candida sp. blood stream infections are also being increasingly recognised.

Lower respiratory tract infection and ventilator-associated pneumonia (VAP) Respiratory syncytial virus (RSV) is the commonest viral agent causing yearly outbreaks. Other viruses (Rhio virus, Adeno Virus, Influenza and Parainfluenza Virus) spread by large droplets from respiratory tract with reported secondary attack rates up to $30 \%$. Viral pneumonias can predispose patients to secondary bacterial infections. VAP is the second common HCAI in PICU with incidence between 0.7 and 5.7 episodes per 1000 ventilation days. Endotracheal intubation provides a ready conduit to the lower respiratory tract with increasing infection risk. Pathogenic organism can be endogenous respiratory flora (H. Influenzae, Moraxella Sp, Streoptococcus pnaeumonae) or translocation of gramnegative bacteria such as Pseudomonas Sp, Escherichia coli.

Skin and surgical site infections The skin is the largest organ forming a physical protective barrier. A breach in skin integrity by surgical procedure or insertion of catheter or pressure sores leads to interruption in defence against infections. Interaction between inoculation of virulent organism, break in integrity with the presence of foreign body (sutures, implants) and host defences determine local surgical site infection or widespread septicaemia. Unsurprisingly, skin flora like Staphylococcus aureus is the commonest pathogen but Pseudomonas Aeruginosa and other gram-negative bacteria are common hospital-acquired pathogens. Worryingly, more infections with multidrug-resistant organism like methicillin-resistant Staphylococcus aureus (MRSA), carbapenemase-producing Enterobacteria (CPE) and fungi are of growing importance.

In procedures likes neurosurgical cerebrospinal fluid shunts coagulase-negative Staphylococci (CONS) form the commonest pathogen. 


\section{Infection control and prevention of healthcare-acquired infection on paediatric intensive care unit}

HCAI are associated with significant morbidity, mortality and financial burden. Protecting patient from preventable HCAI is every team member's responsibility. Though infection control and microbiology teams will be providing specialist input there needs to be an ongoing all round concerted effort to avoid HCAI.

\section{Design and structure of intensive care unit}

There is expert consensus "best practice guideline" for specified clinical areas $[6,15,17]$.

Patient areas in PICU should be a combination of openplan area and isolation cubicles (Fig. 5). New units are planned with minimum ratio of one isolation cubicle to every 2-3 open beds. Each bed space should be $25.5 \mathrm{~m}^{2}$ with design recommendations to facilitate medical and nursing team to care for pateints effectively and safely $[6,15]$.

Health-building notes provide detailed guidelines to developing new or extension of existing hospital building [6].

\section{Infection control programme}

Strategies for infection prevention and control have evolved to current system where there are standard precautions followed for every patient by each healthcare professional in order to prevent spread infection. However, depending on the isolated microorganisms and the mode of transmission, there needs to be special precautions e.g. droplet precautions to prevent transmission of pathogen from respiratory secretions [13]. Airborne precautions where infectious microorganisms remain suspended in air would necessitate isolation in a negativepressure cubicle with special air handing (source isolation).

Contrary to these, immunocompromised patients should be cared for in a positive-pressure room to protect a susceptible host. [7, 9, 16, 22].

\section{Hand hygiene}

Cross infection between patients can be due to indirect contamination with same hand caring for patients. The World Health Organisation initiative on hand hygiene emphasises five moments for hand hygiene (before and after touching a patient, before clean/aseptic procedure, after exposure to body fluid, after touching patient surroundings [8, 13, 14, 17]. Nowadays, alcohol-based hand gels are available to use for visibly clean hands. These are particularly effective in killing microorganisms without risk of antibiotic resistance.

It is vital to have hand hygiene compliance monitored and maintained at highest level.

\section{Personal protective equipment (PPE)}

PPE not only protect the healthcare workers but also cross infection. For specific viral infections with airborne spread, it may be advisable to use specific face mask as per local guidelines.

\section{Aseptic non touch technique (ANTT)}

Poor practices of accessing vascular access devices are fundamental cause of HCAI [19]. Regardless of a vascular access device being peripherally or centrally placed, ANTT should be standard practice $[13,17]$. Focus of ANTT is to minimise microorganism contamination during preparation, administration and delivery of intravenous therapy.

\section{Care bundle for HCAI}

Team-based approach to implement and monitor compliance to specific healthcare-associated infections can improve HCAI rates. There has been stepped intervention programme introduced [3]. Since introduction of multimodal stepped interventions, there has been significant and sustained improvement in CLABSI rates in paediatric and adult intensive care setting $[4,5]$. There are standard care bundles for central lineassociated blood stream infections (CLABSI), ventilator associated pneumonia (VAP) and surgical site infections (SSI) [11, $13,14,17]$.

Chart 2

CLABSI care bundle

(insertion and maintenance and access)

- Aseptic insertion of an appropriate device

- Correct siting of the device

- Effective cutaneous antisepsis: and for continuing care of the device

- Hand decontamination and asepsis for any contact with the device

- Daily observation of the insertion site

- Clean, intact dressing

Chart 3

VAP care bundle

- Elevation of head of bed $\left(30-45^{\circ}\right)$

- Daily sedation review and assessment of readiness to wean and

extubate

- Regular mouth care (2-4 Hourly)

- Change of ventilator circuit when visibly soiled

- Hand hygiene (before and after contact with ventilator circuit

Charts II and III

\section{Screening of patients}

There are different ways to screen patient for colonisation. It can be at admission screening or weekly screening for 

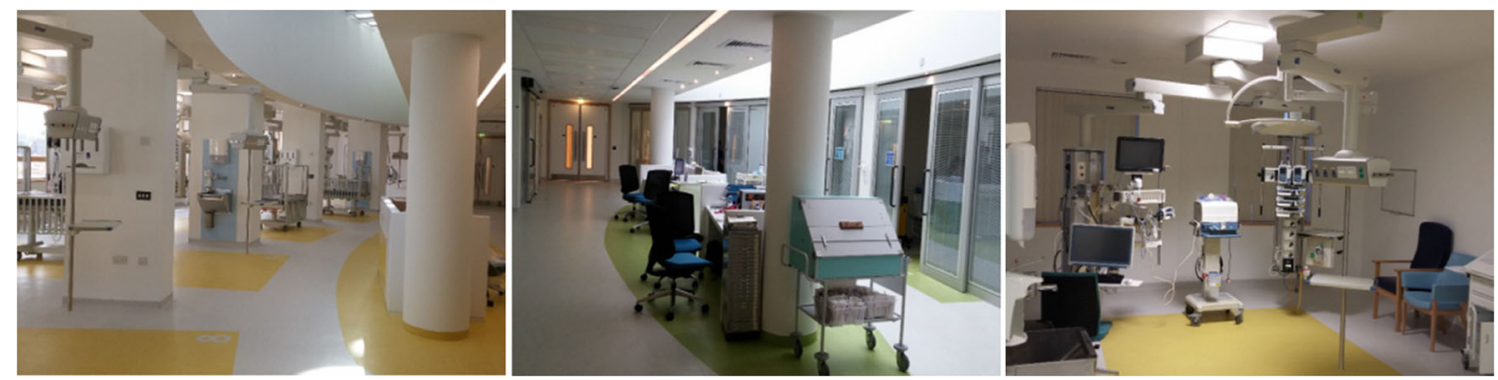

Fig. 5 Design of PICU at the recently built Alder Hey hospital, Liverpool, UK—open plan areas along with isolation cubicles

antibiotic resistant micro-organisms e.g. Methicillin-resistant Staphylococcus aureus (MRSA) or pre-operative screening to determine peri-operative antibiotics prophylaxis as well as specific topical antimicrobial agent application. There are increasing numbers of antibiotics-resistant organism screening tests available. However, various factors need to be considered before implementing these screening programme (likelihood of colonisation, cost, availability of timely reporting, capacity to isolate screened patients,) as they are yet to prove effective in reducing the incidence of HCAI.

\section{Surveillance}

Surveillance is a systematic method of collecting, consolidating and analysing data concerning the distribution and determinants of a given disease or event, followed by the dissemination of that information to those who can improve outcomes $[8,14,16,21,22]$. There are standardised definitions and templates for monitoring of CLABSI (central lineassociated blood stream infections (CLABSI)/ventilator associated pneumonia (VAP)/surgical site infection (SSI)/catheterassociated urinary tract infections (CA UTI). Standard surveillance definitions have been developed by the Centres for Disease Control and prevention (CDC), which allows monitoring of trends, identifying practices associated with prevention of HCAI and comparison or rates within and between facilities [24].

\section{Impact of HCAI}

HCAIs are results of system failure and they are associated with significant adverse outcomes $[2,19,21]$. There is increase in length of intensive care and hospital stay as well as mortality [10]. There are significant financial implications, and the price paid by patient and families to recover from potentially preventable infection is very high [18].

\section{Conclusions}

In summary, there needs to be collaborative working between paediatric intensive care staff, microbiologist and infection control team and a concerted effort to minimise the incidence of HCAI. Introduction of infection control care bundles goes a long way in control of HCAI. Every PICU should have a designated nurse and intensivist infection control lead to ensure implementation of care bundles and to maintain regular of PICU infections. Judicious use of antibiotics in consultation with microbiologist helps keep check on this preventable condition.

\section{Compliance with ethical standards}

Conflict of interest The authors declare they have no conflict of interest.

\section{References}

1. Abulhasan YB, Rachel SP, Châtillon-Angle M-O, Alabdulraheem N, Schiller I, Dendukuri N, Angle MR, Frenette C (2018) Healthcare-associated infections in the neurological intensive care unit: results of a 6-year surveillance study at a major tertiary care center. Am J Infect Control 46:656-662

2. Becerra MR, Tantaleán JA, Suárez VJ, Alvarado MC, Candela JL, Urcia FC (2010) Epidemiologic surveillance of nosocomial infections in a pediatric intensive care unit of a developing country. BMC Pediatr 10:66

3. Bion J, Richardson A, Hibbert P, Beer J, Abrusci T, McCutcheon M, Cassidy J, Eddleston J, Gunning K, Bellingan G, Patten M, Harrison D (2013) Matching Michigan Collaboration \& Writing Committee. "Matching Michigan": a 2-year stepped interventional programme to minimise central venous catheter-blood stream infections in intensive care units in England. BMJ Qual Saf 22:110-123

4. Cassidy J, Campbell G, Martin J, Milner P, Gray J (2018) Abstract O-20: 5 years and 50000 PIC days - how big a problem are health care associated infections (HCAI) in critically ill children. Pediatr Crit Care Med 19:10

5. de Mello MJG, de Albuquerque MF, Lacerda HR, Barbosa MTS, de Alencar Ximenes RA (2010) Risk factors for healthcareassociated infection in a pediatric intensive care unit. Pediatr Crit Care Med 11:246-252

6. Department of Health (2000) Health building note. Critical care units 2000:04-02

7. Ducel G, Fabry J, Nicollle L (2002) Infection control precautions in patient care. WHO, Geneva, chapter V, pp 44-46

8. Fuhrman, Zimmerman (2011) Pediatric critical care. Elsevier B. V., Amsterdam, pp 1349-1363

9. Gray J, Gossain S, Morris K (2001) Three-year survey of bacteremia and fungemia in a pediatric intensive care unit. Pediatr Infect Dis J 20:416-421 
10. Hatachi T, Tachibana K, Takeuchi M (2015) Incidences and influences of device-associated healthcare-associated infections in a pediatric intensive care unit in Japan: a retrospective surveillance study. J Intensive Care 3:44

11. Hellyer TP, Ewan V, Wilson P, Simpson AJ (2016) The Intensive Care Society recommended bundle of interventions for the prevention of ventilator-associated pneumonia. J Intensive Care Soc 17: 238-243

12. Lambert S, Slonim AD (2010) Healthcare-associated infections: working toward eradication of a global problem. Pediatr Intensive Crit Care Soc 11:308-310. https://doi.org/10.1097/PCC. 0b013e3181c0134a

13. Loveday HP, Wilson JA, Pratt RJ, Golsorkhi M, Tingle A, Bak A, Browne J, Prieto J, Wilcox M (2014) epic3: national evidencebased guidelines for preventing healthcare-associated infections in NHS hospitals in England. J Hosp Infect 86(Suppl 1):S1-S70

14. NICE guidelines (2011). Healthcare-associated infections: Prev Control | Guidance and guidelines | URL https://www.nice.org.uk/ guidance/ph36 (accessed 6.20.18)

15. Paediatric Intensive Care Society standards (2015) Standards for the care of critically ill children. Paediatric Intensive Care Society, London

16. Public Health England (2017) Surveillance of Healthcare Associated Infection (HCAI). Public Health England, London

17. Siegel JD, Rhinehart E, Jackson M, Chiarello L; Health Care Infection Control Practices Advisory Committee (2007) 2007 Guideline for isolation precautions: preventing transmission of infectious agents in health care settings. Am J Infect Control 35(10 Suppl 2):S65-164

18. Slonim AD, Kurtines HC, Sprague BM, Singh N (2001) The costs associated with nosocomial bloodstream infections in the pediatric intensive care unit. Pediatr Crit Care Med 2:170-174

19. Stockwell JA (2007) Nosocomial infections in the pediatric intensive care unit: affecting the impact on safety and outcome. Pediatr Crit Care Med 8:S21-S37

20. Tekin R, Dal T, Pirinccioglu H, Oygucu SE (2013) A 4-year surveillance of device-associated nosocomial infections in a neonatal intensive care unit. Pediatr Neonatol 54:303-308. https://doi.org/ 10.1016/j.pedneo.2013.03.011

21. Urrea M, Pons M, Serra M, Latorre C, Palomeque A (2003) Prospective incidence study of nosocomial infections in a pediatric intensive care unit. Pediatr Infect Dis J 22:490-494. https://doi.org/ 10.1097/01.inf.0000069758.00079.d3

22. Wattal C, Khardori N (eds) (2014) Hospital infection prevention Springer India, New Delhi

23. Zingg W, Holmes A et al (2015) Hospital organisation, management, and structure for prevention of health-care-associated infection: a systematic review and expert consensus. Lancet Infect Dis $15: 212-224$

24. Zingg W, Hopkins S, Gayet-Ageron A, Holmes A, Sharland M, Suetens C, ECDC PPS study group (2017) Health-care-associated infections in neonates, children, and adolescents: an analysis of paediatric data from the European Centre for Disease Prevention and Control point-prevalence survey. Lancet Infect Dis 17:381-389 